JPE 14-5-23

\title{
Sliding Mode Control of Three-Phase Four-Leg Inverters via State Feedback
}

\author{
Long-Yue Yang ${ }^{\dagger}$, Jian-Hua Liu ${ }^{*}$, Chong-Lin Wang ${ }^{*}$, and Gui-Fu Du* \\ ${ }^{\dagger *}$ School of Information and Electrical Engineering, China University of Mining and Technology, Xuzhou, China
}

\begin{abstract}
To optimize controller design and improve static and dynamic performances of three-phase four-leg inverter systems, a compound control method that combines state feedback and quasi-sliding mode variable structure control is proposed. The linear coordinate change matrix and the state variable feedback equations are derived based on the mathematical model of three-phase four-leg inverters. Based on system relative degrees, sliding surfaces and quasi-sliding mode controllers are designed for converted linear systems. This control method exhibits the advantages of both state feedback and sliding mode control. The proposed controllers provide flexible dynamic control response and excellent stable control performance with chattering suppression. The feasibility of the proposed strategy is verified by conducting simulations and experiments.
\end{abstract}

Key words: Inverter, Sliding mode control, Voltage control

\section{INTRODUCTION}

Power electronic converters are typical switching nonlinear systems. However, their linear models are generally established to facilitate control. Significant limitations occur when a linear system control method is applied to the controller design of such systems. Research on advanced nonlinear control methods of power electronic converters is the future trend in system design [1]-[5].

With bridge topology and switch components, a three-phase four-leg inverter system can be described as a typical multi-input multi-output (MIMO) system with time-varying and coupled nature [6]-[8]. To satisfy its requirements of dynamic response and control accuracy, the controller should be designed based on nonlinear control theory and technology.

Sliding mode control is a special nonlinear control [9]-[11]. Given that its structure exhibits a switching state as time progresses, system state variables that slide with the preset manifold can be limited. For some systems, sliding mode control presents considerable robustness, which allows it to maintain system control rapidity and stability when the model is uncertain [12]-[15]. With these advantages, sliding mode

Manuscript received Apr. 17, 2014; accepted Jun. 13, 2014

Recommended for publication by Associate Editor Shihua Li.

${ }^{\dagger}$ Corresponding Author: yanglongyue2006@163.com

Tel: +86-13913450882, China University of Mining and Technology

*School of Information and Electrical Engineering, China University of Mining and Technology, China control has been applied to several power electronic converters, such as inverters [16], pulse-width modulation (PWM) rectifiers [17], active power filters [18], and DC-DC converters [19].

In [20], a fixed switching frequency sliding mode controller for a single-phase unipolar inverter was proposed. Chattering was eliminated by smoothing the control law in a narrow boundary layer. In [21], a discrete-time linear state-feedback controller with feedforward compensation was presented for designing the voltage source of DC-AC converters. In [22], the performance of terminal sliding mode control was improved via integral compensation, which eliminates steady-state errors in a DC/AC inverter. Although the sliding mode variable structure control algorithm has been applied to inverters, conventional sliding mode control still has problems. With a sliding surface that is directly designed from a system model, conventional sliding mode controller achieves output voltage control by depending only on its considerable robustness. In this case, the dynamic quality of the sliding mode cannot be optimized. Sliding mode control also has a chattering defect that reduces control accuracy [23], [24]. For power electronic equipment such as inverters, chattering may cause instability as well as chattering of unmolded high-frequency parts of the system. Hence, a sliding mode controller should be improved to decrease chattering at the design stage.

To facilitate controller design and improve the tracing performance of the control system, a control method that combines state feedback and sliding mode control is proposed 


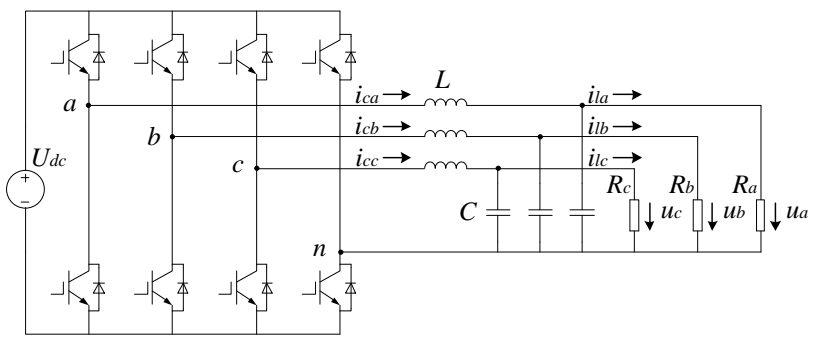

Fig. 1. Schematic of a three-phase, four-leg inverter.

and applied to a three-phase four-leg inverter in this study. Based on the mathematical model for a three-phase four-leg inverter, the linear coordinate change matrix and the state variable feedback equations are derived via diffeomorphism relationship to simplify the inverter model. Controller design and control complexity are simplified by mapping the original complicated system into independent simplified systems. Sliding surfaces and quasi-sliding mode controllers are then designed for converted systems based on system relative degrees [25]-[27]. Simultaneously, the parameters of the controllers are designed according to linear control theory.

The aforementioned method combines the advantages of state feedback control with sliding mode variable structure control. On one hand, a precise linear sliding surface can be established by state feedback. Then, the parameters can be optimized by linear theory, thereby improving the tracking performance of the control system inside the boundary layer. On the other hand, given the invariance of the sliding mode controller to uncertainties and disturbances, the dependence of the state feedback method on an accurate mathematical model is effectively weakened and the robustness of the control system is enhanced. Moreover, the dynamic response outside the boundary layer is improved. Finally, the feasibility and effectiveness of the proposed algorithms are verified by simulations and experiments.

The rest of this paper is organized as follows. Section II presents the constructed mathematical model for a three-phase four-leg inverter, followed by the state feedback of the proposed model. Section III provides the designed sliding surfaces and quasi-sliding mode controllers based on system relative degrees. Subsequently, the parameters of the controllers are designed based on linear control theory. Section IV discusses the simulations and experiments. Finally, Section $\mathrm{V}$ concludes the paper.

\section{STATE FEEDBACK OF A THREE-PHASE FOUR-LEG INVERTER}

\section{A. System Model of a Three-Phase Four-Leg Inverter}

The schematic of a three-phase four-leg inverter is shown in Fig. 1.

$U_{d c}$ denotes the DC power supply voltage. $i_{c a}, i_{c b}$, and $i_{c c}$ denote the inverter inductor currents. $i_{l a}, i_{l b}$, and $i_{l c}$ denote the three-phase load currents. $u_{a}, u_{b}$, and $u_{c}$ denote the output voltages. $L$ is the output filter inductor, and $C$ is the output filter capacitor. $R_{a}, R_{b}$, and $R_{c}$ are the load resistances.

The three-phase pulse modulation variables are defined as $m_{a}, m_{b}$, and $m_{c}$. Assuming that the switch is ideal, and switching dead time, filter inductor resistor, and capacitor resistor are ignored, the mathematical model can be obtained by applying Kirchhoff theorem as follows:

$$
\left\{\begin{array}{l}
C \frac{d u_{a}}{d t}=i_{c a}-u_{a} / R_{a} \\
C \frac{d u_{b}}{d t}=i_{c b}-u_{b} / R_{b} \\
C \frac{d u_{c}}{d t}=i_{c c}-u_{c} / R_{c} \\
L \frac{d i_{c a}}{d t}=-u_{a}+m_{a} U_{d c} \\
L \frac{d i_{c b}}{d t}=-u_{b}+m_{b} U_{d c} \\
L \frac{d i_{c c}}{d t}=-u_{c}+m_{c} U_{d c}
\end{array} .\right.
$$

The mathematical model presented in Eq. (1) shows that a three-phase four-leg inverter is a linear MIMO system.

The objective of a three-phase four-leg inverter is to control the output voltage that tracks references through PWM. The output voltage and inductor current are defined as state variable $\boldsymbol{X}=\left[\begin{array}{llllll}x_{1} & x_{2} & x_{3} & x_{4} & x_{5} & x_{6}\end{array}\right]^{\mathrm{T}}=\left[\begin{array}{llllll}u_{a} & u_{b} & u_{c} & i_{c a} & i_{c b} & i_{c c}\end{array}\right]^{\mathrm{T}}$; switch function is defined as the input variable $\boldsymbol{U}=\left[\begin{array}{lll}u_{1} & u_{2} & u_{3}\end{array}\right]^{\mathrm{T}}=\left[\begin{array}{lll}m_{a} & m_{b} & m_{c}\end{array}\right]^{\mathrm{T}}$; and voltage error is defined as output variable $\boldsymbol{Y}=\boldsymbol{H}[\boldsymbol{X}(\mathrm{t})]^{\mathrm{T}}=\left[\begin{array}{lll}h_{1}(\boldsymbol{X}) & h_{2}(\boldsymbol{X}) & h_{3}(\boldsymbol{X})\end{array}\right]^{\mathrm{T}}=\left[\begin{array}{lll}u_{\text {aref }}-X_{1} & u_{\text {bref }}-X_{2}\end{array}\right.$ $\left.u_{\text {cref }}-X_{3}\right]^{\mathrm{T}} . u_{\text {aref }}, u_{\text {bref }}$, and $u_{\text {cref }}$ are the references of the three-phase output voltages.

An affine nonlinear system model of a three-phase four-leg inverter can be described as follows:

$$
\left\{\begin{array}{l}
\dot{\boldsymbol{X}}=f[\boldsymbol{X}(t)]+g_{1}[\boldsymbol{X}(t)] u_{1}+g_{2}[\boldsymbol{X}(t)] u_{2}+g_{3}[\boldsymbol{X}(t)] u_{3}, \\
\boldsymbol{Y}=\boldsymbol{H}(\boldsymbol{X})
\end{array},\right.
$$

where $\quad f(\boldsymbol{X})=\left[\frac{x_{4}}{C}-\frac{x_{1}}{R_{a} C}, \frac{x_{5}}{C}-\frac{x_{2}}{R_{b} C}, \frac{x_{6}}{C}-\frac{x_{3}}{R_{C} C},-\frac{x_{1}}{L},-\frac{x_{2}}{L},-\frac{x_{3}}{L}\right]^{T}$, $g_{1}(\boldsymbol{X})=\left[0,0,0, U_{d c} / L, 0,0\right]^{T}, \quad g_{2}(\boldsymbol{X})=\left[0,0,0,0, U_{d c} / L, 0\right]^{T}, \quad$ and $g_{3}(\boldsymbol{X})=\left[0,0,0,0,0, U_{d c} / L\right]^{T}$.

\section{B. State Feedback of a Three-phase Four-leg Inverter}

$L_{f} h=(\partial h / \partial \boldsymbol{X}) f$ is defined as the Lie derivative of $f$ and $h$. The control variable of the systems after the state feedback is defined as $\boldsymbol{V}=\left[v_{1}, v_{2}, v_{3}\right]^{\mathrm{T}}$. The new state variables can then be designed as follows:

$$
\left\{\begin{array}{l}
z_{1}=h_{1}(\boldsymbol{X})=u_{\text {aref }}-x_{1} \\
z_{2}=L_{f} h_{1}(\boldsymbol{X})=\frac{x_{1}}{R_{a} C}-\frac{x_{4}}{C} \\
z_{3}=h_{2}(\boldsymbol{X})=u_{\text {bref }}-x_{2} \\
z_{4}=L_{f} h_{2}(\boldsymbol{X})=\frac{x_{2}}{R_{b} C}-\frac{x_{5}}{C} \\
z_{5}=h_{3}(\boldsymbol{X})=u_{c r e f}-x_{3} \\
z_{6}=L_{f} h_{3}(\boldsymbol{X})=\frac{x_{3}}{R_{C} C}-\frac{x_{6}}{C}
\end{array} .\right.
$$


According to Eq. (3), the relationship among the new state variables can be expressed as follows:

$$
\left\{\begin{array}{l}
\dot{z}_{1}=\frac{\partial h_{1}(\boldsymbol{X})}{\partial \boldsymbol{X}} \dot{\boldsymbol{X}}=\frac{x_{1}}{R_{a} C}-\frac{x_{4}}{C}=z_{2} \\
\dot{z}_{2}=\frac{\partial\left(L_{f} h_{1}(\boldsymbol{X})\right)}{\partial \boldsymbol{X}} \dot{\boldsymbol{X}}=\left(\frac{1}{L C}-\frac{1}{R_{a}^{2} C^{2}}\right) x_{1}+\frac{x_{4}}{R_{a} C^{2}}-\frac{U_{d c}}{L C} u_{1} \\
\dot{z}_{3}=\frac{\partial h_{2}(\boldsymbol{X})}{\partial \boldsymbol{X}} \dot{\boldsymbol{X}}=\frac{x_{2}}{R_{b} C}-\frac{x_{5}}{C}=z_{4} \\
\dot{z}_{4}=\frac{\partial\left(L_{f} h_{2}(\boldsymbol{X})\right)}{\partial \boldsymbol{X}} \dot{\boldsymbol{X}}=\left(\frac{1}{L C}-\frac{1}{R_{b}^{2} C^{2}}\right) x_{2}+\frac{x_{5}}{R_{b} C^{2}}-\frac{U_{d c}}{L C} u_{2} \\
\dot{z}_{5}=\frac{\partial h_{3}(\boldsymbol{X})}{\partial \boldsymbol{X}} \dot{\boldsymbol{X}}=\frac{x_{3}}{R_{C} C}-\frac{x_{6}}{C}=z_{6} \\
\dot{z}_{6}=\frac{\partial\left(L_{f} h_{3}(\boldsymbol{X})\right)}{\partial \boldsymbol{X}} \dot{\boldsymbol{X}}=\left(\frac{1}{L C}-\frac{1}{R_{c}^{2} C^{2}}\right) x_{3}+\frac{x_{6}}{R_{c} C^{2}}-\frac{U_{d c}}{L C} u_{3}
\end{array} .\right.
$$

By setting $\dot{z}_{2}=v_{1}, \dot{z}_{4}=v_{2}$, and $\dot{z}_{6}=v_{3}$, we transform the original complicated system into the following simplified system:

$$
\dot{Z}=A Z+B V,
$$

where $\boldsymbol{A}=\left[\begin{array}{llllll}0 & 1 & 0 & 0 & 0 & 0 \\ 0 & 0 & 0 & 0 & 0 & 0 \\ 0 & 0 & 0 & 1 & 0 & 0 \\ 0 & 0 & 0 & 0 & 0 & 0 \\ 0 & 0 & 0 & 0 & 0 & 1 \\ 0 & 0 & 0 & 0 & 0 & 0\end{array}\right], \quad \boldsymbol{B}=\left[\begin{array}{lll}0 & 0 & 0 \\ 1 & 0 & 0 \\ 0 & 0 & 0 \\ 0 & 1 & 0 \\ 0 & 0 & 0 \\ 0 & 0 & 1\end{array}\right]$.

Hence, the relationship between the original control variable $\boldsymbol{U}$ and the new one $\boldsymbol{V}$ is as follows:

$$
\left\{\begin{array}{l}
u_{1}=\frac{L C}{U_{d c}}\left[\left(\frac{1}{L C}-\frac{1}{R_{a}^{2} C^{2}}\right) x_{1}+\frac{x_{4}}{R_{a} C^{2}}-v_{1}\right] \\
u_{2}=\frac{L C}{U_{d c}}\left[\left(\frac{1}{L C}-\frac{1}{R_{b}^{2} C^{2}}\right) x_{2}+\frac{x_{5}}{R_{b} C^{2}}-v_{2}\right] . \\
u_{3}=\frac{L C}{U_{d c}}\left[\left(\frac{1}{L C}-\frac{1}{R_{c}^{2} C^{2}}\right) x_{3}+\frac{x_{6}}{R_{c} C^{2}}-v_{3}\right]
\end{array}\right.
$$

The equivalent block diagram is shown in Fig. 2. The part of the block diagram in the dashed box is the original system.

\section{Design OF SLiding Mode VARIABLE STRUCTURE CONTROLLER}

\section{A. Design of Sliding Surface}

The purpose of a three-phase four-leg inverter is to control the output voltage that tracks references. This task is a tracking control problem, the target of which is $\boldsymbol{X}^{*}=\left[u_{\text {aref }}, u_{\text {bref }}, u_{\text {cref }}\right]^{\mathrm{T}}$. Through state feedback, the state-space equilibrium point of system (5) is determined as $Z^{*}=[0,0,0]^{\mathrm{T}}$. The tracking problem of the original system is then transformed into a stabilization problem.

Therefore, the control aim of the system is to find a suitable control law $\boldsymbol{V}$. Under this control law, the system is asymptotically stable with an excellent dynamic response at $Z^{*}$.

Eq. (5) implies that the system is mapped to three independent simplified linear systems after state feedback.

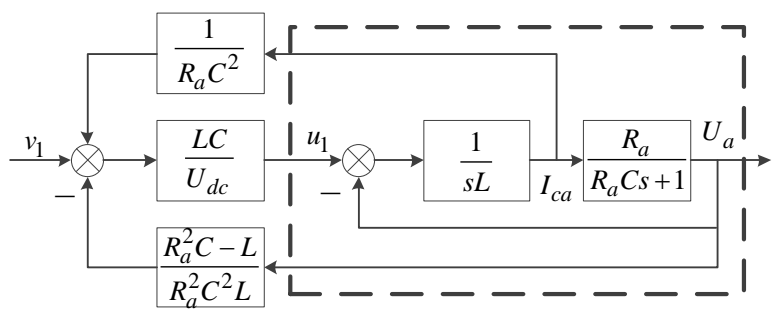

Fig. 2. Diagram of an inverter system based on state feedback.

System relative degree is defined as $r$. A sliding mode control can be designed to make the system output dynamics, that is, $d^{i} z / d t^{i}$ for $(1 \leq i \leq r)$, satisfy the following $r$-order dynamic equation:

$$
\left(\frac{d^{r} z}{d t^{r}}+\sum_{j=0}^{r-1} \lambda_{j} \frac{d^{j} z}{d t^{j}}\right)-\left(\frac{d^{r} z^{*}}{d t^{r}}+\sum_{j=0}^{r-1} \lambda_{j} \frac{d^{j} z^{*}}{d t^{j}}\right)=0,
$$

where $z^{*}$ is the desired output reference needed to be tracked by the system. This last relation must be satisfied when the sliding regime is achieved, which can be accomplished by identifying Eq. (7) with the invariance condition $\dot{\sigma}=0$, that is,

$$
\dot{\sigma}=\left(\frac{d^{r} z}{d t^{r}}+\sum_{j=0}^{r-1} \lambda_{j} \frac{d^{j} z}{d t^{j}}\right)-\left(\frac{d^{r} z^{*}}{d t^{r}}+\sum_{j=0}^{r-1} \lambda_{j} \frac{d^{j} z^{*}}{d t^{j}}\right)=0 .
$$

The sliding surface is derived by the following simple integration:

$$
\sigma=\frac{d^{r-1}\left(z-z^{*}\right)}{d t^{r-1}}+\sum_{j=1}^{r-1} \lambda_{j} \frac{d^{j-1}\left(z-z^{*}\right)}{d t^{j-1}}+\lambda_{0} \int\left(z-z^{*}\right) d t
$$

The tracking error dynamics is exponentially stable if the coefficients $\lambda_{0}, \ldots, \lambda_{r-1}$ are chosen such that the Laplace $s$-polynomial, that is,

$$
s^{r}+\lambda_{r-1} s^{r-1}+\cdots+\lambda_{0}=0,
$$

is Hurtwitz (all poles are within the left half side of the Laplace plane).

For the output variable function $h_{1}(\boldsymbol{X})=u_{\text {aref }}-\boldsymbol{X}_{1}$, the Lie derivatives can be calculated as follows:

$$
\left\{\begin{array}{l}
L_{g_{1}} h_{1}(\boldsymbol{X})=\frac{\partial h_{1}(\boldsymbol{X})}{\partial \boldsymbol{X}} g_{1}(\boldsymbol{X})=0 \\
L_{g_{2}} h_{1}(\boldsymbol{X})=\frac{\partial h_{1}(\boldsymbol{X})}{\partial \boldsymbol{X}} g_{2}(\boldsymbol{X})=0 \\
L_{g_{3}} h_{1}(\boldsymbol{X})=\frac{\partial h_{1}(\boldsymbol{X})}{\partial \boldsymbol{X}} g_{3}(\boldsymbol{X})=0 \\
L_{f} h_{1}(\boldsymbol{X})=\frac{\partial h_{1}(\boldsymbol{X})}{\partial \boldsymbol{X}} f(\boldsymbol{X})=\frac{x_{1}}{R_{a} C}-\frac{x_{4}}{C} \\
L_{g_{1}} L_{f} h_{1}(\boldsymbol{X})=\frac{\partial\left(L_{f} h_{1}(\boldsymbol{X})\right)}{\partial \boldsymbol{X}} g_{1}(\boldsymbol{X})=-\frac{U_{d c}}{L C} \neq 0 \\
L_{g_{2}} L_{f} h_{1}(\boldsymbol{X})=\frac{\partial\left(L_{f} h_{1}(\boldsymbol{X})\right)}{\partial \boldsymbol{X}} g_{2}(\boldsymbol{X})=0 \\
L_{g_{3}} L_{f} h_{1}(\boldsymbol{X})=\frac{\partial\left(L_{f} h_{1}(\boldsymbol{X})\right)}{\partial \boldsymbol{X}} g_{3}(\boldsymbol{X})=0
\end{array} .\right.
$$

The relative degree of $h_{1}(\boldsymbol{X})$ is $r_{1}=2$. Similarly, relative degrees are obtained as $r_{2}=r_{3}=2$ for $h_{2}(\boldsymbol{X})=u_{\text {bref }}-x_{2}$ and $h_{3}(\boldsymbol{X})=u_{\text {cref }}-x_{3}$.

For the case of the A-phase subsystem, we design the sliding 
mode variable structure controller as follows. The A-phase subsystem can be expressed as Eq. (12), with a relative degree of $r_{1}=2$ and a control target of $z_{1}{ }^{*}=0$.

$$
\left\{\begin{array}{l}
\dot{z}_{1}=z_{2} \\
\dot{z}_{2}=v_{1}
\end{array}\right.
$$

From Eq. (9), we obtain the following sliding surface:

$$
\begin{aligned}
\sigma_{1} & =\frac{d\left(z_{1}-z_{1}^{*}\right)}{d t}+\lambda_{1} \frac{d\left(z_{1}-z_{1}^{*}\right)}{d t}+\lambda_{0} \int\left(z_{1}-z_{1}^{*}\right) d t \\
& =z_{2}+\lambda_{1} z_{1}+\lambda_{0} \int z_{1} d t
\end{aligned}
$$

\section{B. Sliding Mode Controller Design}

Based on the sliding surface, we can derive the equivalent control $v_{1 e q}$ as the continuous control input that forces $\dot{\sigma}_{1}=0$, that is,

$$
v_{1 e q}=-\lambda_{1} z_{2}-\lambda_{0} z_{1}
$$

According to the general rules of the sliding mode variable structure control, the system can reach a switching manifold within a limited time. However, the switching ripple for a power electronic converter is amplified because of the inherent chattering phenomenon in sliding mode controls. A particular approach law designed for sliding mode control can generally reduce chattering while maintaining the robustness of variable structure control.

The quasi-sliding mode control is chosen as the approach law based on the boundary layer. The adoption of the saturation function $\operatorname{sat}(\sigma / \Delta)$ enables the controller to exist as a normal sliding mode variable structure control outside the boundary layer and as a continuous state feedback control inside the boundary layer, which weakens chattering.

Boundary layer thickness is defined as $\Delta$. The approach law can then be expressed as follows:

$$
v_{1 n}=-\varepsilon \cdot \operatorname{sat}\left(\sigma_{1} / \Delta\right),
$$

where $\Delta>0, \varepsilon>0, \quad \operatorname{sat}\left(\sigma_{1} / \Delta\right)=\left\{\begin{array}{ll}+1, & \sigma_{1}>\Delta \\ \sigma_{1} / \Delta, & \left|\sigma_{1}\right| \leq \Delta \\ -1, & \sigma_{1}<-\Delta\end{array}\right.$.

The control law is equivalent to a constant approach law with considerable robustness outside boundary layer $\Delta$. Given the existence of the boundary layer, the $\varepsilon$ value can be a large constant. In this manner, feedback gain is increased to ensure fast tracking control. Inside the boundary layer $\Delta$, continuous feedback control achieves an ideal sliding mode by sacrificing robustness to suppress chattering.

The subsystem controllers of B- and C-phases can also be obtained based on the symmetry of the three-phase system. By using Eqs. (14) and (15), we can achieve the three-phase sliding mode controller as follows:

$$
V=\left[\begin{array}{c}
v_{1} \\
v_{2} \\
v_{3}
\end{array}\right]=\left[\begin{array}{c}
v_{1 e q}+v_{1 n} \\
v_{2 e q}+v_{2 n} \\
v_{3 e q}+v_{3 n}
\end{array}\right]=\left[\begin{array}{l}
-\lambda_{1} z_{2}-\lambda_{0} z_{1}-\varepsilon \cdot \operatorname{sat}\left(\sigma_{1} / \Delta\right) \\
-\lambda_{1} z_{4}-\lambda_{0} z_{3}-\varepsilon \cdot \operatorname{sat}\left(\sigma_{2} / \Delta\right) \\
-\lambda_{1} z_{6}-\lambda_{0} z_{5}-\varepsilon \cdot \operatorname{sat}\left(\sigma_{3} / \Delta\right)
\end{array}\right] .
$$

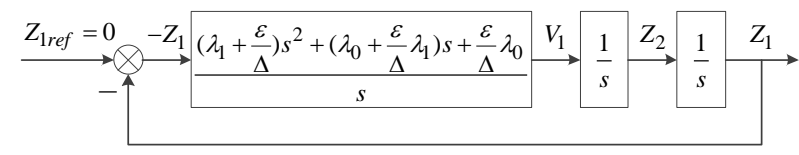

Fig. 3. Control system block diagram $(\mid \sigma \leq \Delta)$.

\section{Analyzing the Sliding Mode Controller}

The three-phase linear control system can be obtained by substituting $\boldsymbol{V}$ from Eq. (16) into Eq. (12). Then, we can analyze the control system in A-phase.

1) When $|\sigma| \leq \Delta$ : the controller transfer function can be expressed as follows:

$$
G_{c 1}(s)=-\frac{\left(\lambda_{1}+\frac{\varepsilon}{\Delta}\right) s^{2}+\left(\lambda_{0}+\frac{\varepsilon}{\Delta} \lambda_{1}\right) s+\frac{\varepsilon}{\Delta} \lambda_{0}}{s} .
$$

The control system block diagram is shown in Fig. 3.

The closed-loop transfer function of the control system is as follows:

$$
\Phi(s)=\frac{s^{3}}{s^{3}+\left(\lambda_{1}+\frac{\varepsilon}{\Delta}\right) s^{2}+\left(\lambda_{0}+\frac{\varepsilon}{\Delta} \lambda_{1}\right) s+\frac{\varepsilon}{\Delta} \lambda_{0}} .
$$

The control system shown in Eq. (18) is a third-order linear system. The system parameters can be designed according to linear theory.

The parameters can be selected by using the pole assignment method. The system poles are installed as a negative real (exponential decay term) and a complex conjugate pair (attenuation sine term). The denominator of Eq. (18) can be obtained as follows:

$$
\begin{aligned}
& s^{3}+\left(\lambda_{1}+\frac{\varepsilon}{\Delta}\right) s^{2}+\left(\lambda_{0}+\frac{\varepsilon}{\Delta} \lambda_{1}\right) s+\frac{\varepsilon}{\Delta} \lambda_{0} \\
& =\left(s+s_{0}\right)\left(s^{2}+2 \zeta \omega_{n} s+\omega_{n}^{2}\right) \\
& =s^{3}+\left(2 \zeta \omega_{n} s+s_{0}\right) s^{2}+\left(2 \zeta \omega_{n} s_{0}+\omega_{n}^{2}\right) s+\omega_{n}^{2} s_{0}
\end{aligned} .
$$

The closed-loop poles of the system are $s_{1}=-s_{0}, s_{2,3}=-\zeta \omega_{n} \pm \omega_{n} \sqrt{\zeta^{2}-1}$.

Based on the stability condition, the closed-loop poles of the system are all located on the left half side of the Laplace plane. Hence, the real parts of the selected poles are negative $\left(s_{0}>0, \zeta \omega_{n}>0\right) . s_{2}$ and $s_{3}$ are chosen as the dominant poles, and $s_{0}>5 \times \zeta \omega_{n}$ is satisfied. System step response attenuates slowly when the distance between a pole and the imaginary axis is short, and vice versa. Therefore, the transient characteristics of a system are mainly affected by the conjugate poles. According to linear system theory, dynamic performance can be regulated by adjusting the values of $\zeta$ and $\omega_{n}$.

2) When $|\sigma|>\Delta$ : the control system is nonlinear.

The control system block diagram is shown in Fig. 4.

For the open-loop system, a large constant $\varepsilon$ is added as a feedforward to system control. In this manner, the open-loop gain is amplified to improve the robustness of the control system. 


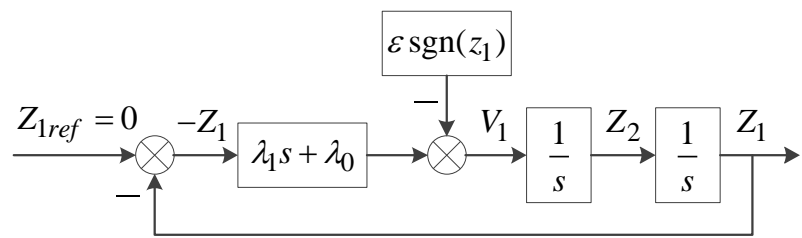

Fig. 4. Control system block diagram $(|\sigma|>\Delta)$.
TABLE I

PARAMETERS OF THE SYSTEM

\begin{tabular}{|c|c|c|}
\hline Inverter output voltage & $u$ (Peak value) & $100 \mathrm{~V}$ \\
DC bus voltage & $U_{d c}$ & $200 \mathrm{~V}$ \\
Filter inductor & $L$ & $5 \mathrm{mH}$ \\
Filter capacitor & $C$ & $5 \mathrm{uF}$ \\
Switching frequency & $f$ & $5 \mathrm{kHz}$ \\
\hline
\end{tabular}

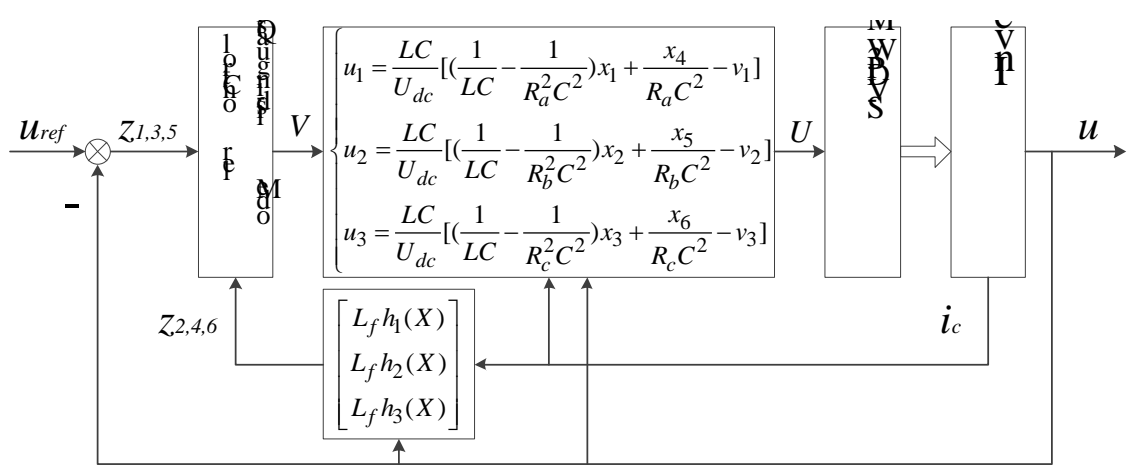

Fig. 5. Control block diagram of a three-phase four-leg inverter.

According to Eqs. (6) and (16), the variable structure controller that is transformed into the original system is as follows:

$$
\left\{\begin{array}{c}
\begin{array}{rl}
u_{1}= & \frac{L C}{U_{d c}}\left[\left(\frac{1}{L C}-\frac{1}{R_{a}^{2} C^{2}}\right) x_{1}+\frac{x_{4}}{R_{a} C^{2}}+\lambda_{1}\left(\frac{x_{1}}{R_{a} C}-\frac{x_{4}}{C}\right)\right. \\
& \left.+\lambda_{0}\left(u_{\text {aref }}-x_{1}\right)+\varepsilon \cdot \operatorname{sat}\left(s_{1} / \Delta\right)\right]
\end{array} \\
\begin{array}{c}
u_{2}=\frac{L C}{U_{d c}}\left[\left(\frac{1}{L C}-\frac{1}{R_{b}^{2} C^{2}}\right) x_{2}+\frac{x_{5}}{R_{b} C^{2}}+\lambda_{1}\left(\frac{x_{2}}{R_{b} C}-\frac{x_{5}}{C}\right)\right. \\
\left.\quad+\lambda_{0}\left(u_{b r e f}-x_{2}\right)+\varepsilon \cdot \operatorname{sat}\left(s_{2} / \Delta\right)\right]
\end{array} \\
\begin{array}{c}
u_{3}=\frac{L C}{U_{d c}}\left[\left(\frac{1}{L C}-\frac{1}{R_{C}^{2} C^{2}}\right) x_{3}+\frac{x_{6}}{R_{C} C^{2}}+\lambda_{1}\left(\frac{x_{3}}{R_{C} C}-\frac{x_{6}}{C}\right)\right. \\
\left.\quad+\lambda_{0}\left(u_{c r e f}-x_{3}\right)+\varepsilon \cdot \operatorname{sat}\left(s_{3} / \Delta\right)\right]
\end{array} .
\end{array}\right.
$$

The resistor $R_{a}, R_{b}, R_{c}$ parameters can be identified through output voltages and currents. Pulses are modulated by using a 3D space vector PWM (SVPWM) algorithm.

Fig. 5 shows the control block diagram of a three-phase four-leg inverter.

\section{SIMULATIONS AND EXPERIMENTS}

\section{A. Design of the System Parameters}

MATLAB/Simulink software is used in this study to analyze the control system. A low-power three-phase four-leg inverter prototype is built to verify the feasibility of the proposed algorithm. The main structure of the inverter is shown in Fig. 1. The DC power source consists of a voltage regulator and a three-phase rectifier. The inverter loads are resistances. The insulated-gate bipolar transistor switches are GD100HFT120C2S from Starpower Semiconductor Ltd. (Jiaxing, China). The proposed sliding control is implemented into a TMS320F28335 digital signal processor from Texas Instruments, Inc. (Texas, USA) with a $10 \mathrm{kHz}$ sampling frequency.

The system parameters are provided in Table I.

Through simulations and comparisons, the optimum control parameters are selected as $\zeta=0.707, \omega_{n}=7.071$, and $s_{0}=30>5 \times \zeta \omega_{n}$.

The closed-loop poles of the system are $s_{1}=-s_{0}=-30$ and $s_{2,3}=-5 \pm 5 j$. From Eq. (19), we obtain the following:

$$
\left\{\begin{array}{l}
\lambda_{1}+\varepsilon / \Delta=2 \zeta \omega_{n} s+s_{0} \\
\lambda_{0}+(\varepsilon / \Delta) \lambda_{1}=2 \zeta \omega_{n} s_{0}+\omega_{n}^{2} . \\
(\varepsilon / \Delta) \lambda_{0}=\omega_{n}^{2} s_{0}
\end{array} .\right.
$$

The controller parameters are obtained as $\lambda_{0}=50, \lambda_{1}=10$, and $\varepsilon / \Delta=30$ by eliminating imaginary roots. The boundary layer can be selected as $\Delta<\max \left(\left|\sigma_{1}\right|\right) / 2$ and is valued as $\Delta=50$ in the experiment. To verify the correctness and effectiveness of the proposed control algorithm, dynamic response and steady-state performance are analyzed under the same conditions.

\section{B. Unbalanced Load Experiment}

Inverter output voltage and current simulation steady-state waveforms with unbalanced resistive loads are shown in Fig. 6. The load parameters are $R_{a}=20 \Omega, R_{b}=15 \Omega$, and $R_{c}=10 \Omega$. The output root mean square (RMS) voltages in Fig. 6 are $U_{a}=70.27 \mathrm{~V}, U_{b}=70.85 \mathrm{~V}$, and $U_{c}=71.04 \mathrm{~V}$. In this figure, the output voltages present smooth waveforms, small distortions, and symmetry, although the loads are asymmetric. 


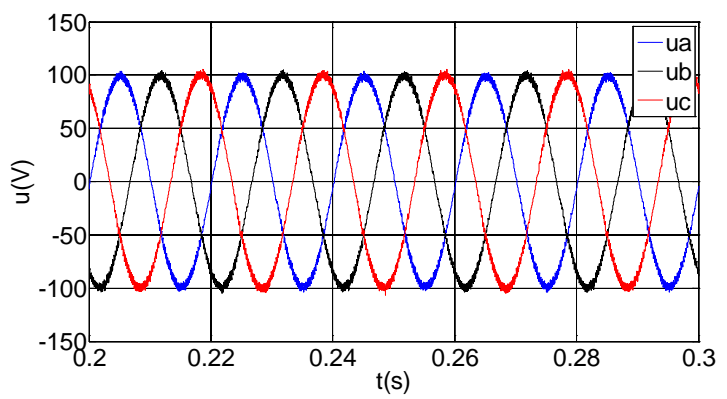

(a)



(b)

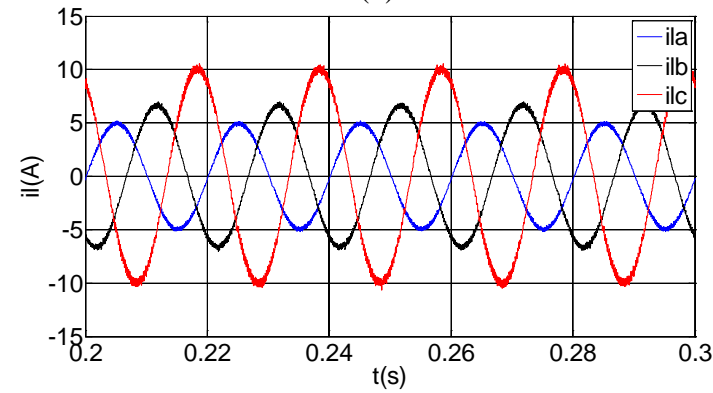

(c)

Fig. 6. System simulation waveforms with three-phase unbalanced resistive loads. (a) Three-phase output voltages. (b) Inductor currents. (c) Load currents.

A TDS2014 oscilloscope (Tektronix, Inc., Oregon, USA) is used as the experiment measuring instrument. Fig. 7(a) shows the output voltage experimental waveforms, whereas Fig. 7(b) presents the output current experimental waveforms. The experiment results agree with the simulation results.

Simulations and experiments are also conducted on unbalanced resistance-inductance loads and nonlinear loads. Resistance-inductance loads are chosen as $R_{a}=R_{b}=R_{c}=10 \Omega, L_{a}=2 \mathrm{mH}, L_{b}=4 \mathrm{mH}$, and $L_{c}=8 \mathrm{mH}$. The simulation waveforms are shown in Fig. 8. With results similar to resistive loads, currents are asymmetric, whereas voltages are symmetric. Fig. 9 shows the three-phase voltages and C-phase current experimental waveforms under the same condition. To compare their phase relationship, voltage and current are shown in the same figure.

A-phase load is chosen as the series that comprises a diode and a resistance, others as resistances, and $R_{a}=R_{b}=R_{c}=10 \Omega$. According to the simulation waveforms in Fig. 10, balanced output voltages can be achieved under unbalanced nonlinear loads. The experimental waveforms in Fig. 11 verify the simulation results.

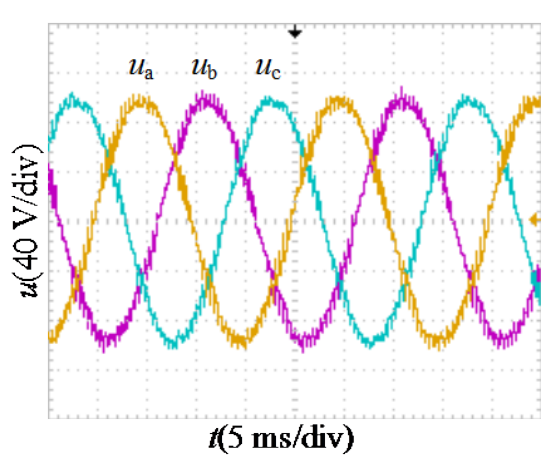

(a)

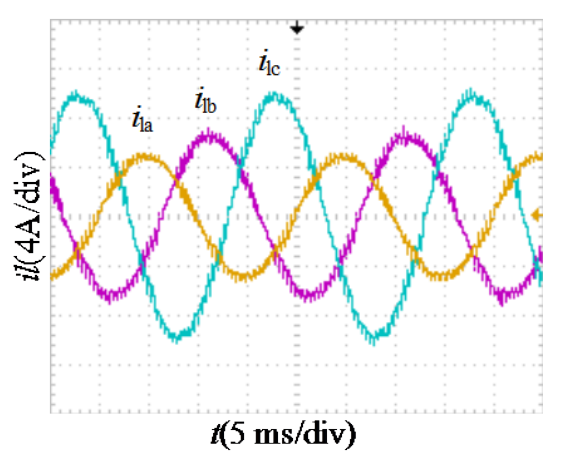

(b)

Fig. 7. System experimental waveforms with three-phase unbalanced resistive loads. (a) Three-phase output voltages. (b) Load currents.

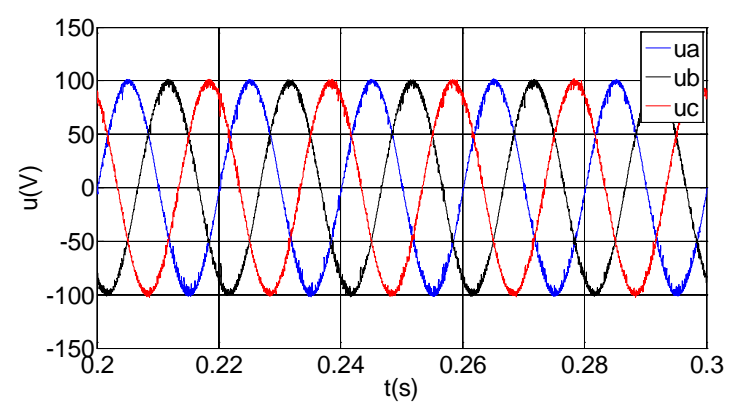

(a)



(b)

Fig. 8. System simulation waveforms with three-phase unbalanced resistance-inductance loads. (a) Three-phase output voltages. (b) Load currents.

\section{Output Voltage Tracking Experiment}

Considering that the nature of the load has an insignificant effect on the results under transient conditions,we still adopt 




Fig. 9. System experimental waveforms with three-phase unbalanced resistance-inductance loads.

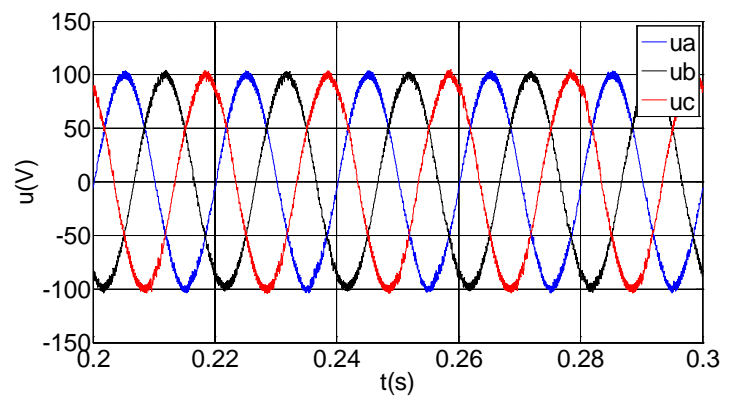

(a)

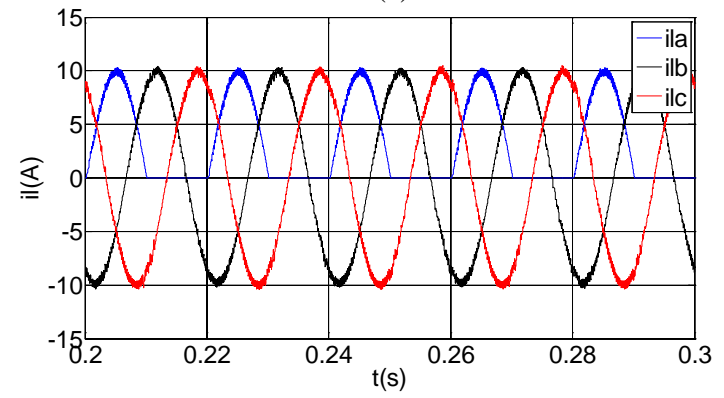

(b)

Fig. 10. System simulation waveforms with three-phase nonlinear loads. (a) Three-phase output voltages. (b) Load currents.

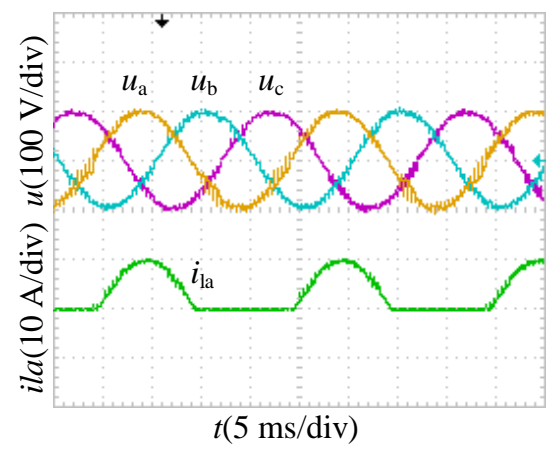

Fig. 11. System experimental waveforms with three-phase nonlinear loads.

resistive loads for analysis and comparison.

Fig. 12 shows the system voltage tracking performance under an unbalanced load condition. The load parameters are $R_{a}=20 \Omega, R_{b}=15 \Omega$, and $R_{c}=10 \Omega$. The initial output voltages are $U_{a}=70.7 \mathrm{~V}, U_{b}=70.7 \mathrm{~V}$, and $U_{c}=70.7 \mathrm{~V}$ (rms).

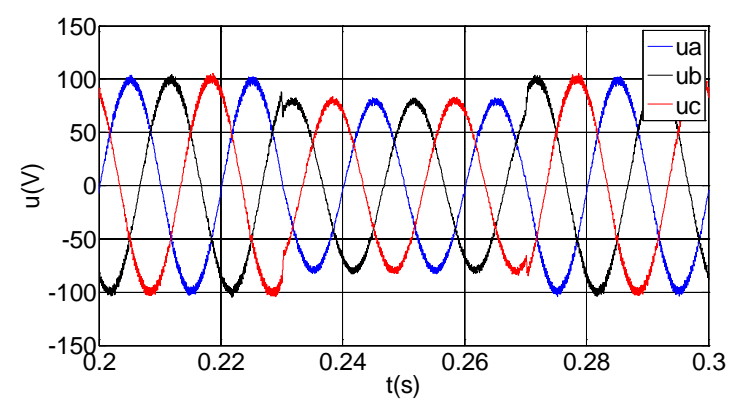

(a)

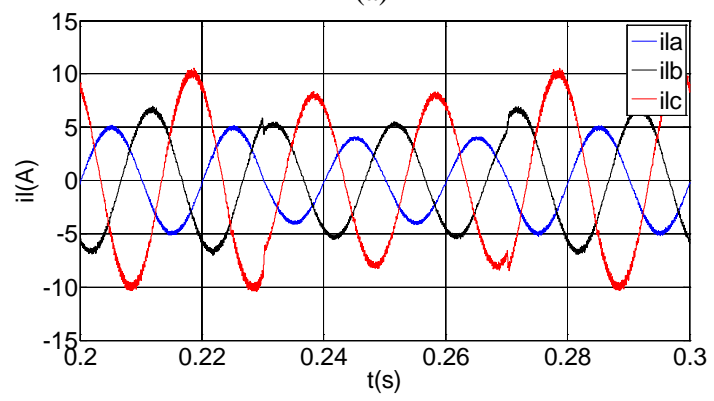

(b)

Fig. 12. System simulation waveforms of voltage tracking. (a) Three-phase output voltages. (b) Load currents.



Fig. 13. System experimental waveforms of voltage tracking.

$U_{a}=U_{b}=U_{c}=56.5 \mathrm{~V}$ are assigned to the reference voltages at $0.23 \mathrm{~s}$ and adjusted to the original given values at $0.27 \mathrm{~s}$. After the mutation of the reference voltage value, output voltage amplitude changes and restores stability rapidly. The currents reach a new steady state within a short period. Then, the three-phase output voltages track the new references without static error. The preceding analyses show that the control system exhibits good tracking performance.

Fig. 13 depicts the three-phase voltage experimental response to reference mutation, which proves that the system exhibits excellent voltage tracking performance.

\section{Load Disturbance Experiment}

Fig. 14 shows the output voltage and current waveforms of the inverter with load disturbance. The initial loads are $R_{a}=R_{b}=R_{c}=20 \Omega$. The loads at $0.23 \mathrm{~s}$ are adjusted to $R_{a}=20 \Omega, R_{b}=15 \Omega$, and $R_{c}=10 \Omega$. The amplitude of the output voltage initially exhibits small fluctuations but stability is soon restored. Thus, the control system demonstrates strong 


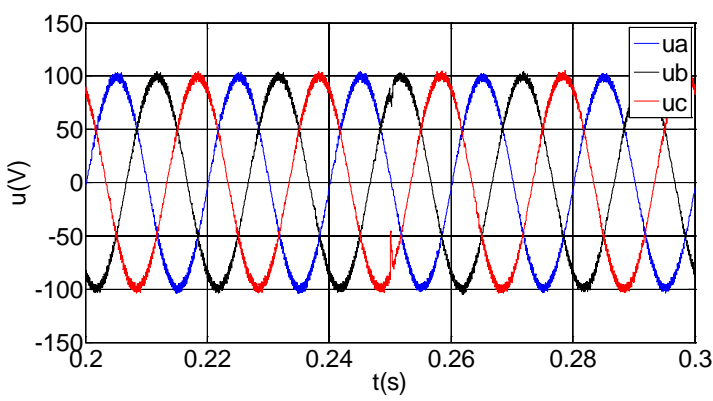

(a)

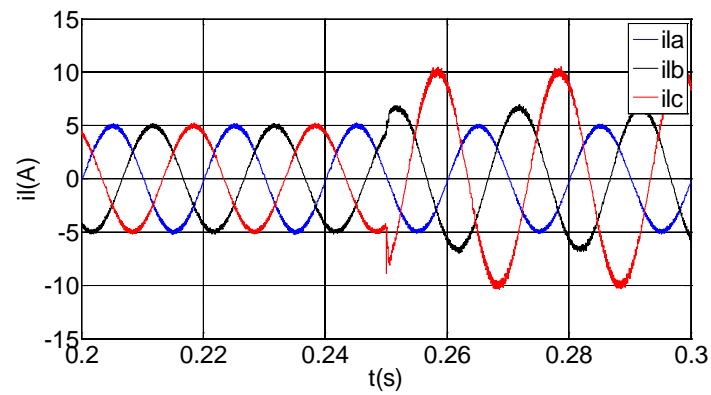

(b)

Fig. 14. System simulation waveforms with load disturbance. (a) Three-phase output voltages. (b) Load currents.

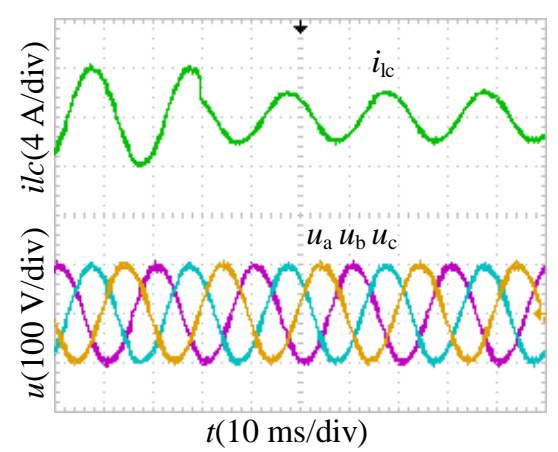

Fig. 15. System experimental waveforms with load disturbance

resistance against load disturbance.

The experimental three-phase voltages and C-phase load current waveforms are shown in Fig. 15. Given the experimental limitations, only the C-phase load is adjusted. After load mutation, load current changes rapidly, whereas load voltage remains stable.

\section{E. DC Bus Voltage Disturbance Experiment}

Fig. 16 depicts the simulation waveform of an inverter with DC bus voltage disturbance. The mutation time and amplitude of the DC bus voltage are shown in Fig. 16(a). Output voltage and load current are substantially stable when the DC bus voltage fluctuates. The proposed controller achieves strong resistance against DC bus voltage disturbance.

Fig. 17 shows the experimental waveforms of the DC bus voltage and three-phase output voltages. The experiment

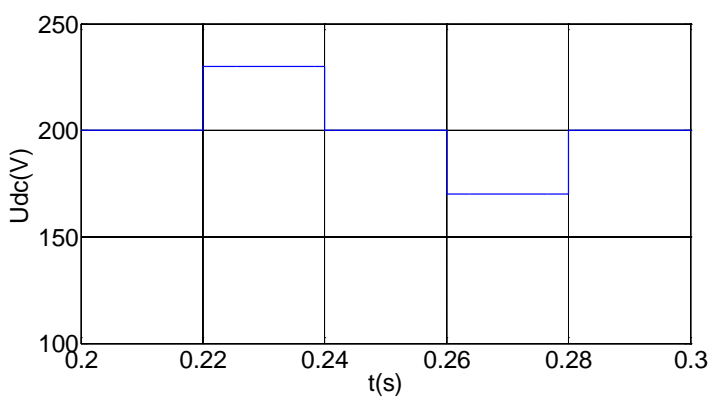

(a)

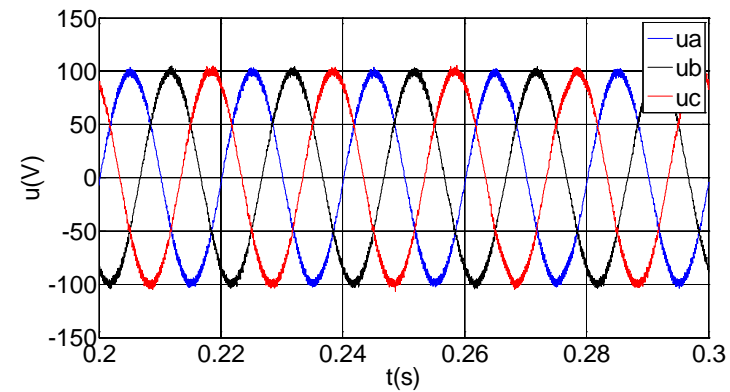

(b)

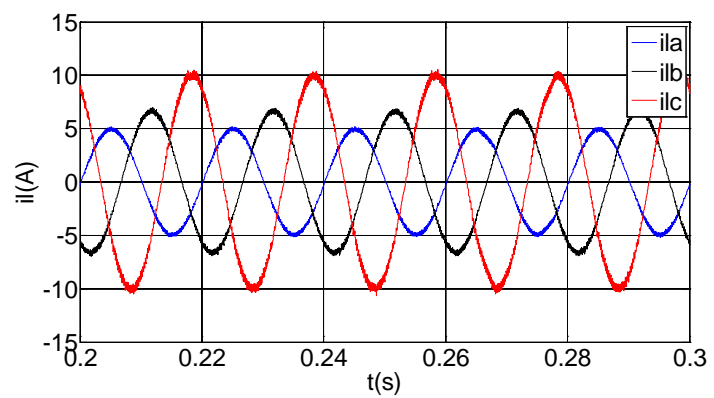

(c)

Fig. 16. System simulation waveforms with DC bus voltage disturbance. (a) DC bus voltage. (b) Three-phase output voltages. (c) Load currents.

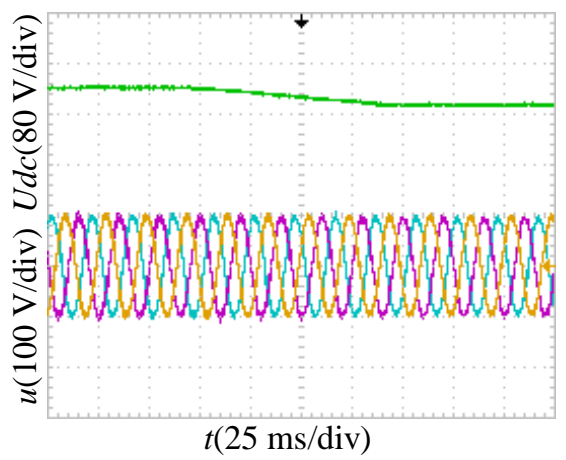

Fig. 17. System experimental waveforms with DC bus voltage disturbance.

results agree with the simulation results.

Good control performances can be achieved in the steady and transient states with strong anti-interference capability and robustness. The simulation and experiment results indicate that the new sliding mode control method is effective. 


\section{CONCLUSIONS}

This study proposes a compound control method that combines state feedback and quasi-sliding mode variable structure control for a three-phase four-leg inverter system. The original complicated system is mapped into independent simplified systems by deriving the linear coordinate change matrix and the state variable feedback equations. According to system relative degrees, sliding surfaces and quasi-sliding mode controllers are designed for the linear systems. Normal sliding mode variable structure control is adopted outside the boundary layer, whereas continuous state feedback control is adopted inside the boundary layer, which weakens chattering. The proposed controllers provide flexible dynamic control response and excellent stable control performance with chattering suppression. The feasibility of the proposed strategy is verified through simulations and experiments.

\section{ACKNOWLEDGMENT}

This work is supported by the National Natural Science Foundation of China (Grant No. 51107143) and the Jiangsu Provincial Natural Science Foundation of China (Grant No. BK20130187).

\section{REFERENCES}

[1] J. P. Richard, "Time-delay systems: an overview of some recent advances and open problems," Automatica, Vol. 39, No. 10, pp. 1667-1694, Oct. 2003.

[2] E. Twining and D. G. Holmes, "Grid current regulation of a three-phase voltage source inverter with an LCL input filter," IEEE Trans. Power Electron., Vol. 18, No. 3, pp. 888-895, May 2003.

[3] S. Rahmani, N. Mendalek, and K. Al-Haddad, "Experimental design of a nonlinear control technique for three-phase shunt active power filter," IEEE Trans. Ind. Electron., Vol. 57, No. 10, pp. 3364-3375, Oct. 2010.

[4] S. T. Yang, Q. Lei, F. Z. Peng, and Z. M. Qian, "a robust control scheme for grid-connected voltage-source inverters,” IEEE Trans. Ind. Electron., Vol. 58, No. 1, pp. 202-212, Jan. 2011.

[5] T. Hornik and Q. C. Zhong, “A current-control strategy for voltage-source inverters in microgrids based on H-infinity and repetitive control,” IEEE Trans. Power Electron., Vol. 26, No. 3, pp. 943-952, Mar. 2011.

[6] G. Dong and O. Ojo, "Current regulation in four-leg voltage-source converters,” IEEE Trans. Ind. Electron., Vol. 54, No. 4, pp. 2095-2105, Aug. 2007.

[7] L. Vechiu, O. Curea, and H. Camblong, "Transient operation of a four-leg inverter for autonomous applications with unbalanced load,” IEEE Trans. Power Electron., Vol. 25, No. 2, pp. 399-407, Feb. 2010.

[8] R. Zhang, V. H. Prasad, D. Boroyevich, and F. C. Lee, "Three-dimensional space vector modulation for four-leg voltage-source converters,” IEEE Trans. Power Electron., Vol. 17, No. 3, pp. 314-326, May 2002.

[9] Y. W. He, W. S. Xu, and Y. Cheng, "A novel scheme for sliding-mode control of DC-DC converters with a constant frequency based on the averaging model,” Journal of Power
Electronics, Vol. 10, No. 1, pp. 1-8, Jan. 2010.

[10] A. Levant, "Quasi-continuous high-order sliding-mode controllers,” IEEE Trans. Automat. Contr., Vol. 50, No. 11, pp. 1812-1816, Nov. 2005.

[11] S. C. Tan, Y. M. Lai, and C. K. Tse, "General design issues of sliding-mode controllers in dc-dc converters," IEEE Trans. Ind. Electron., Vol. 55, No. 3, pp. 1160-1174, Mar. 2008.

[12] J. Yang, J. Y. Su, S. H. Li, and X. H. Yu, "High-order mismatched disturbance compensation for motion control systems via a continuous dynamic sliding-mode approach,” IEEE Trans. Ind. Inform., Vol. 10, No. 1, pp. 604-614, Feb. 2014.

[13] J. Yang, S. H. Li, and X. H. Yu, "Sliding-mode control for systems with mismatched uncertainties via a disturbance observer," IEEE Trans. Ind. Electron., Vol. 60, No. 1, pp. 160-169, Jan. 2013.

[14] J. Yang, S. H. Li, J. Y. Su, and X. H. Yu, "Continuous nonsingular terminal sliding mode control for systems with mismatched disturbances," Automatica, Vol. 49, No. 7, pp. 2287-2291, Jul. 2013.

[15] M. Defoort, F. Nollet, T. Floquet, and W. Perruquetti, “A third-order sliding-mode controller for a stepper motor," IEEE Trans. Ind. Electron., Vol. 56, No. 9, pp. 3337-3346, Sep. 2009.

[16] S. Ryvkin, R. Schmidt-Obermoeller, and A. Steimel, "Sliding-mode-based control for a three-level inverter drive,” IEEE Trans. Ind. Electron., Vol. 55, No. 11, pp. 3828-3835, Nov. 2008.

[17] M. G. Umamaheswari, G. Uma, and K. M. Vijayalakshmi, "Analysis and design of reduced-order sliding-mode controller for three-phase power factor correction using Cuk rectifiers,” IET Power Electron., Vol. 6, No. 5, pp. 935-945, 2013.

[18] J. Matas, L. G. de Vicuna, J. Miret, J. M. Guerrero, and M. Castilla, "Feedback linearization of a single-phase active power filter via sliding mode control," IEEE Trans. Power Electron., Vol. 23, No. 1, pp. 116-125, Jan. 2008.

[19] J. Matas, L. G. de Vicuna, J. Miret, J. M. Guerrero, and M. Castilla, "Feedback linearization of a single-phase active power filter via sliding mode control," IEEE Trans. Power Electron., Vol. 23, No. 1, pp. 116-125, Jan. 2008.

[20] A. Abrishamifar, A. A. Ahmad, and M. Mohamadian, "Discrete-time control for DC-AC converters based on sliding mode design,” IET Power Electron., Vol. 5, No. 6, pp. 833-840, 2012.

[21] L. Schirone, F. Celani, and M. Macellari, "Design of voltage tracking control for DC-DC boost converter via total sliding-mode technique," IEEE Trans. Ind. Electron., Vol. 58, No. 6, pp. 2502-2511, Jun. 2011.

[22] F. J. Chang, E. C. Chang, T. J. Liang, and J. F. Chen, "Digital-signal-processor-based DC/AC inverter with integral-compensation terminal sliding-mode control," IET Power Electron., Vol. 4, No. 1, pp. 159-167, Jan. 2011.

[23] I. Boiko, L. Fridman, A. Pisano, and E. Usai, "Analysis of chattering in systems with second-order sliding modes," IEEE Trans. Automat. Contr., Vol. 52, No. 11, pp. 2085-2102, Nov. 2007.

[24] H. Lee and V. I. Utkin, "Chattering suppression methods in sliding mode control systems," Annual Reviews in Control, Vol. 31, No. 2, pp. 179-188, 2007.

[25] K. H. Kim, Y. C. Jeung, D. C. Lee, and H. G. Kim, "LVRT scheme of PMSG wind power systems based on feedback linearization,” IEEE Trans. Power Electron., Vol. 27, No. 5, pp. 2376-2384, May 2012. 
[26] T. L. Chien, C. C. Chen, and C. J. Huang, "Feedback linearization control and its application to MIMO cancer immunotherapy,” IEEE Trans. Contr. Syst. Technol., Vol. 18, No. 4, pp. 953-961, Jul. 2010.

[27] J. Jung, S. Lim, and K. Nam, “A feedback linearizing control scheme for a PWM converter-inverter having a very small DC-Link capacitor,” IEEE Trans. Ind. Appl., Vol. 35, No. 5, pp. 1124-1131, Sep./Oct. 1999.

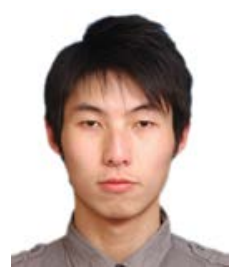

Long-Yue Yang was born in Anhui Province, China in 1988. He received his B.S. in Electrical Engineering and Automation from China University of Mining and Technology (CUMT), Xuzhou, China in 2010. He is currently working toward his Ph.D. in Electrical Engineering at the School of Information and Electrical Engineering, CUMT. His current research interests include power electronics, electric energy quality, and nonlinear control theory.

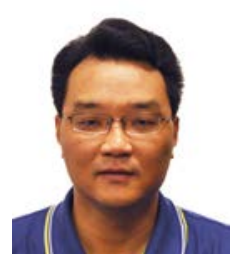

Jian-Hua Liu was born in Henan Province, China in 1973. He received his B.S. in Electrical Engineering and Automation and his Ph.D. in Electrical Engineering from CUMT, Xuzhou, China in 1997 and 2008, respectively. He has been with the School of Information and Electrical Engineering, CUMT since 1999. He is currently an associate professor and a master tutor. His current research interests include smart grid and electrical safety.

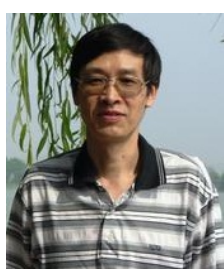

Chong-Lin Wang was born in Anhui Province, China in 1956. He received his B.S. in Electrical Engineering and Automation, and M.S. and Ph.D. in Electrical Engineering from CUMT, Xuzhou, China in 1981, 1989, and 1997, respectively. He has been a professor at the School of Information and Electrical Engineering, CUMT since 1999. He has also been the chief professor of the Electrical Safety and Intelligent Electrical Equipment Research Institute, CUMT since the same year. His main research interests are arc suppression coil and electrical safety.

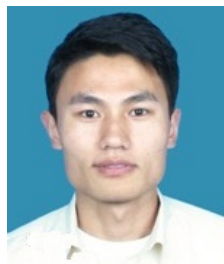

Gui-Fu Du was born in Shandong Province, China in 1990. He received his B.S. in Electrical Engineering and Automation from CUMT, Xuzhou, China in 2012. He is currently working toward his Ph.D. in Electrical Engineering at the School of Information and Electrical Engineering, CUMT. His current research interests include electrical safety, electric energy quality, and DC traction power system. 